\title{
Antioxidant activity of the fractions from water lettuce (Pistia stratiotes) extract
}

\author{
Herpandi, Lestari, S.D., Bastian and "Sudirman, S. \\ Fisheries Product Technology, Faculty of Agriculture, Universitas Sriwijaya, Ogan Ilir Regency 30862, \\ South Sumatra, Indonesia
}

\begin{abstract}
Article history:
Received: 9 October 2020

Received in revised form: 14

November 2020

Accepted: 18 January 2021

Available Online: 29 April

2021
\end{abstract}

Keywords:

Antioxidant,

Free radicals,

Hydroxyl group,

Pistia stratiotes,

Separation

DOI:

https://doi.org/10.26656/fr.2017.5(2).578

\begin{abstract}
Free radicals including reactive oxygen species are continuously increasing in the human body. This condition causes the unbalance between free radicals and antioxidants in the human body. An antioxidant is a compound with the ability to reduce the harmfulness of the free radical. This study aimed to determine the antioxidant activity of fractions and analyzed the functional groups of water lettuce (Pistia stratiotes) methanol extract. The separation process was performed by using thin-layer chromatography (TLC) and column chromatography. The separated fractions were measured for their antioxidant activity by using the 2,2'-diphenyl-1-picrylhydrazyl radical (DPPH) assay. The functional groups of each fraction were determined by using Fourier-transform infrared (FT-IR) spectroscopy. The separation of water lettuce extract by using column chromatography produced seven fractions with different colors and confirmed by using TLC. The antioxidant activity showed the highest activity in the third fraction with a half-maximal inhibitory concentration $\left(\mathrm{IC}_{50}\right)$ value of $131.66 \mathrm{ppm}$. The fifth fraction with the $\mathrm{IC}_{50}$ was about $184.62 \mathrm{ppm}$. Whereas, the first, second, fourth, sixth, and seventh fractions were relatively weak with the $\mathrm{IC}_{50}$ more than $200 \mathrm{ppm}$. The FT-IR spectrum also showed that the intensity hydroxyl group in the third fraction higher than the seventh fraction.
\end{abstract}

\section{Introduction}

Reactive oxygen species (ROS) and free radicals, such as anion superoxide $\left(\mathrm{O}_{2}{ }^{-}\right)$, hydroxyl radical $(\cdot \mathrm{OH})$, and hydrogen peroxide $\left(\mathrm{H}_{2} \mathrm{O}_{2}\right)$ are continuous increases in the human body (Phaniendra et al., 2014). The high level of free radicals compared to antioxidants leading to oxidative stress conditions. This condition is involved in some chronic and low-inflammation diseases, such as insulin resistance in type-2 diabetes, rheumatoid arthritis, cardiovascular diseases, and aging disease (Khansari et al., 2009). Therefore, the body needs exogenous antioxidants through functional food products, fruits, vegetables, and food supplements (Bouayed and Bohn, 2010).

An antioxidant is a compound with the ability to reduce the harmfulness of the free radicals (Lobo et al., 2010). According to its source, the antioxidant can be divided into two groups include endogenous (primary) antioxidants, such as superoxide dismutase (SOD), catalase (Cat), and glutathione peroxidase (GPx), whereas the second group is exogenous (secondary) antioxidants. This type of antioxidant can get from the diet by eating antioxidant-rich foods or food supplements (Bouayed and Bohn, 2010). Water lettuce is one of the aquatic plants which possess antioxidant properties. This plant also contains some bioactive compounds, such as polyphenols, flavonoids, and saponin (Sudirman, Herpandi, Lestari et al., 2017; Sudirman, Herpandi, Nopianti et al., 2017). According to the previous study, water lettuce (Pistia stratiotes) methanol extract showed high antioxidant activity when compared to $n$-hexane and ethyl acetate extracts. This extract is composed of polyphenols and flavonoids (Sudirman, Herpandi, Lestari et al., 2017). A previous study reported polyphenols reduced the harmfulness of the free radical by transferring the hydrogen $(\mathrm{H})$ atom from their hydroxyl (OH) groups (Foti, 2007).

However, in the previous study, the authors used a crude extract of the water lettuce. Therefore, in the present study, we tried to separate the methanol crude extract by using thin-layer chromatography (TLC) and column chromatography. The TLC and column chromatography methods have been widely used to separate plant extract into several fractions (Kagan and Flythe, 2014). A previous study reported that different 
fractions in Garcinia hombroniana methanol extracts also show different antioxidant activities (Triadisti et al., 2018). In addition, separated-fraction also enhanced the antioxidant activity of the extract (Zhao et al., 2019). According to these conditions, we hypothesized that the antioxidant activity of the water lettuce methanol extract will be increased after the separation process. Therefore, this study aimed to investigate the antioxidant activity of methanol fraction from water lettuce (Pistia stratiotes) after separation and confirm their hydroxyl group by Fourier-transform infrared.

\section{Materials and methods}

\subsection{Water lettuce extraction}

The fresh form of water lettuce (Pistia stratiotes) was collected at swampy waters in Palembang city, South Sumatera, Indonesia, and cleaned to remove unwanted materials. Then, it was reduced the size, dried, and extract by the following previous method (Sudirman, Herpandi, Nopianti et al., 2017). Briefly, $20 \mathrm{~g}$ of dried sample was extracted by using $200 \mathrm{~mL}$ of methanol $(1: 10, \mathrm{v} / \mathrm{v})$ at room temperature for $24 \mathrm{hrs}$. The solution was filtrated by using a filter paper, solvent removed by using a rotary vacuum evaporator, and dried by using an oven dryer. The sample was kept for future analysis. The percent of extraction yield was calculated from the weight of dried extract divided by the weight of the dried sample and multiplied by $100 \%$.

\subsection{Separation process}

The thin-layer chromatography (TLC) and column chromatography methods have been widely used to separate fractions from plant extracts. The silica TLC plate and silica gel were purchased from Merck KGaA (Darmstadt, Germany). The TLC method in this research followed the previous study (Kagan and Flythe, 2014). Briefly, the plant extract was dissolved in methanol to have a sample concentration. The TLC plate was cut in a piece $(2 \times 10 \mathrm{~cm})$ and leaving a $1 \mathrm{~cm}$ border on the upperand bottom sides of the plate. The sample was loaded by using a microliter syringe on the plate band and allow to dry. The plate with the sample was then developed in the cover chamber which containing mixed solvents or eluent (methanol-ethyl acetate-acetone $1: 1: 1, \mathrm{v} / \mathrm{v} / \mathrm{v}$, for this study). After the developing step, the plate was dried and observed bands under visible or UV light $(254 \mathrm{~nm}$ and $365 \mathrm{~nm}$ ) then marked bands with a pencil. The mixed solvent was used to further separation by using silica gel column chromatography. Whereas, the column chromatography was performed by the following previous method (Venkatesh et al., 2017). The mixed solvent was loaded into the packed silica column. The seven different separated fractions (confirmed by TLC) were collected, dried, and kept for future analysis.

\subsection{Antioxidant activity assay}

The antioxidant activity assay was performed by the 1,1-diphenyl-2-picrylhydrazyl (DPPH) method as described by the previous method (Molyneux, 2004). The DPPH powder was purchased from Merck KGaA (Darmstadt, Germany). Briefly, each of the dried fractions was dissolved in a methanol solvent to make a serial concentration $(50 \mathrm{ppm}, 100 \mathrm{ppm}, 150 \mathrm{ppm}$, and 200 ppm). Whereas, Vitamin C (containing ascorbic acid) was used as a positive control. A hundred sixty (160) $\mu \mathrm{L}$ of dried-fraction was added into a well containing $40 \mu \mathrm{L}$ of $0.76 \mathrm{mM}$ of DPPH (10 mg DPPH in $10 \mathrm{~mL}$ of methanol). The solution was incubated at $37^{\circ} \mathrm{C}$ for 30 mins. after incubation time, the absorbance was immediately measured at $517 \mathrm{~nm}$ by using spectrophotometry. The percent of inhibition (\%) was calculated from absorbance of blank minus absorbance of the sample divided by absorbance of blank and multiplied by $100 \%$.

\subsection{Functional group analysis}

The functional group was analyzed by using a Fourier transform-infrared (FT-IR) spectroscopy according to the previous methods (Ouhaddouch et al., 2019). Briefly, the sample was placed into the infrared beam (sample holder), then measured in the spectral range between $500 \mathrm{~cm}^{-1}$ and $4000 \mathrm{~cm}^{-1}$. Whereas, $\mathrm{KBr}-$ pressed disk was used in the FT-IR spectroscopy (Spectrum One Perkin Elmer, Massachusetts, USA).

\section{Results and discussion}

This study demonstrated the antioxidant activity of the fractions from the Water lettuce (Pistia stratiotes) methanol extract. The previous studies reported that the methanol extract is composed of polyphenols, such as flavonoids and tannin (Sudirman, Herpandi, Lestari et al., 2017; Sudirman, Herpandi, Nopianti et al., 2017). These studies also reported that methanol extract showed the highest antioxidant activity compared to $n$-hexane and ethyl acetate extracts. In addition, methanol extract also shows a high yield extract (Benhammou et al., 2009). Therefore, this present study only separated the methanol extract from water lettuce to some fractions. The yield of water lettuce methanol extract was about $16.16 \%$. A previous study also reported that methanol is the best solvent for the extraction of leaves of Acalypha wilkesiana and Atriplex halimus were about $14.67 \%$ and $24.00 \%$, respectively (Benhammou et al., 2009; Anokwuru et al., 2016). Methanol has been widely used for bioactive extraction from the plant. Methanol is also 
more efficient in the extraction of polyphenols especially the low molecular weight (MW) of polyphenols (Do et al., 2014).

The fractions from methanol extract were separated by using thin-layer chromatography (TLC) and column chromatography methods. Based on the TLC results, we found that the best-mixed solvent is composed of methanol, ethyl acetate, and acetone with the ratio of $1: 1: 1$, as shown in Figure 1A. According to this result, this eluent was used for the mobile phase in column chromatography. After separation by column chromatography, the result showed that there are seven fractions of the methanol extracts as shown in Figure 1B. The TLC and column chromatography methods have been widely used to separate plant extract into several fractions (Kagan and Flythe, 2014).

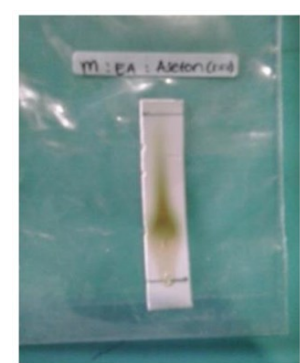

(A)

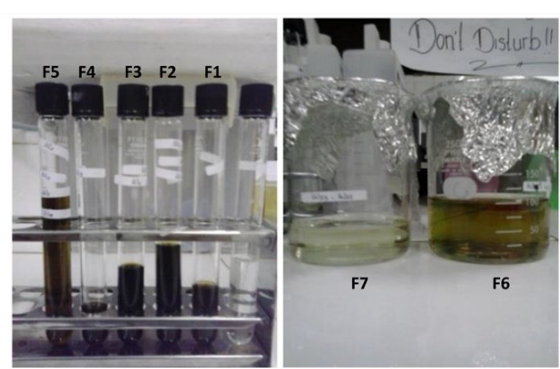

(B) the antioxidant activity of the extract due to its speed, simplicity, and low cost (Alam et al., 2013). As shown in Table 1, third (F3) and fifth (F5) fractions possessed highly antioxidant activities with the half-maximum inhibitory concentration $\left(\mathrm{IC}_{50}\right)$ was about $131.66 \mathrm{ppm}$ and $184.62 \mathrm{ppm}$, respectively. Whereas, other fractions showed weak antioxidant activities with the $\mathrm{IC}_{50}$ more than $200 \mathrm{ppm}$ (Molyneux, 2004). A previous study reported that $\mathrm{IC}_{50}$ of crude methanol extract of water lettuce was about $147.60 \mathrm{ppm}$ (Sudirman, Herpandi, Lestariet al., 2017). The different fractions in Garcinia hombroniana methanol extracts also show different antioxidant activities (Triadisti et al., 2018). In addition, separated-fraction also enhanced the antioxidant activity of the extract (Zhao et al., 2019).

According to the antioxidant activity assay, the highest activity (third, F3) fraction was continued for analysis of its functional group by using Fourier transform-infrared (FT-IR) spectroscopy then compared to the seventh fraction (F7) as a representative from the fraction of weak antioxidant activity as shown in Figure 2 and Table 2. A previous study reported that different bounds of the molecule also show different vibrational frequencies of FTIR spectroscopy, such as $\mathrm{C}-\mathrm{C}, \mathrm{C}=\mathrm{C}, \mathrm{C}$ $-\mathrm{O}, \mathrm{C}=\mathrm{O}, \mathrm{O}-\mathrm{H}$, and $\mathrm{N}-\mathrm{H}$ bonds (Altemimi et al., 2017). The functional group of each wavenumber in Table 2 was evaluated according to the previous reference (Ouhaddouch et al., 2019). Figure 2 showed that the O-H bond in the F3 fraction $\left(3432.90 \mathrm{~cm}^{-1}\right)$ more than the F7 fraction $\left(3366.06 \mathrm{~cm}^{-1}\right)$. The number of $\mathrm{OH}$ groups bound to the aromatic ring is positively correlative with

Figure 1. Methanol Extract Separation: (A) Thin-Layer Chromatography and (B) the Separated-fractions after Separation Process by using Column Chromatography. F1 F7 are the sample fractions.

The antioxidant activity of the fraction was evaluated by using the 1,1-diphenyl-2-picrylhydrazyl (DPPH) method. The DPPH method was widely used to measure

Table 1. The antioxidant activity of the fractions.

\begin{tabular}{lcccccccc}
\hline Sample & F1 & F2 & F3 & F4 & F5 & F6 & F7 & VC \\
\hline $\mathrm{IC}_{50}(\mathrm{ppm})$ & 642.97 & 203.9 & 131.66 & 459.61 & 184.62 & $>2000$ & $>2000$ & 4.14 \\
\hline
\end{tabular}

$\mathrm{F}$ : sample fraction, $\mathrm{IC}_{50}$ : Half-maximum inhibitory concentration, $\mathrm{VC}$ : vitamin $\mathrm{C}$ as a positive control.

Table 2. The functional groups of third fraction and seventh fraction.

\begin{tabular}{cccc}
\hline Sample & $\begin{array}{c}\text { Wavenumber } \\
\left(\mathrm{cm}^{-1}\right)\end{array}$ & $\begin{array}{c}\text { Wavenumber } \\
\text { reference }\left(\mathrm{cm}^{-1}\right)\end{array}$ & Functional groups \\
\hline & 3432.9 & $3200-3500$ & $\mathrm{O}-\mathrm{H}$ \\
Third fraction & 2926.65 & $2800-3000$ & $\mathrm{C}-\mathrm{H}$ \\
(F3) & 1636.94 & $1560-1640$ & $\mathrm{~N}-\mathrm{H}$ \\
& 1459.52 & $1400-1500$ & $\mathrm{C}-\mathrm{H}$ \\
& 1076.63 & $1020-1250$ & $\mathrm{C}-\mathrm{N}, \mathrm{C}-\mathrm{O}, \mathrm{C}-\mathrm{C}$ \\
\hline & 3366.06 & $3200-3500$ & $\mathrm{O}-\mathrm{H}$ \\
& 2962.64 & & \\
Seventh fraction & 2935.11 & $2800-3000$ & $\mathrm{C}-\mathrm{H}$ \\
(F7) & 2875.55 & & \\
& 1659.39 & $1560-1640$ & $\mathrm{~N}-\mathrm{H}$ \\
& 1633.23 & & \\
& 1466.62 & $1400-1500$ & $\mathrm{C}-\mathrm{H}$ \\
& 1434.52 & & \\
& 1065.38 & $1020-1250$ & $\mathrm{C}-\mathrm{N}, \mathrm{C}-\mathrm{O}, \mathrm{C}-\mathrm{C}$ \\
\hline
\end{tabular}




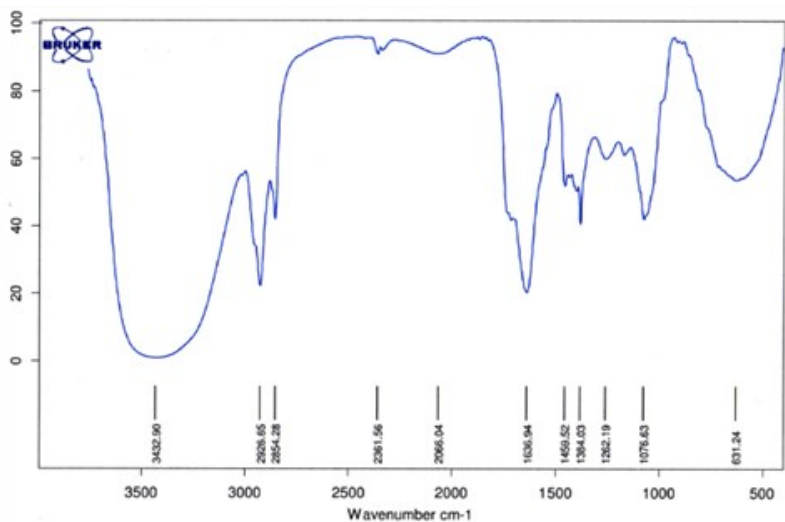

(A)

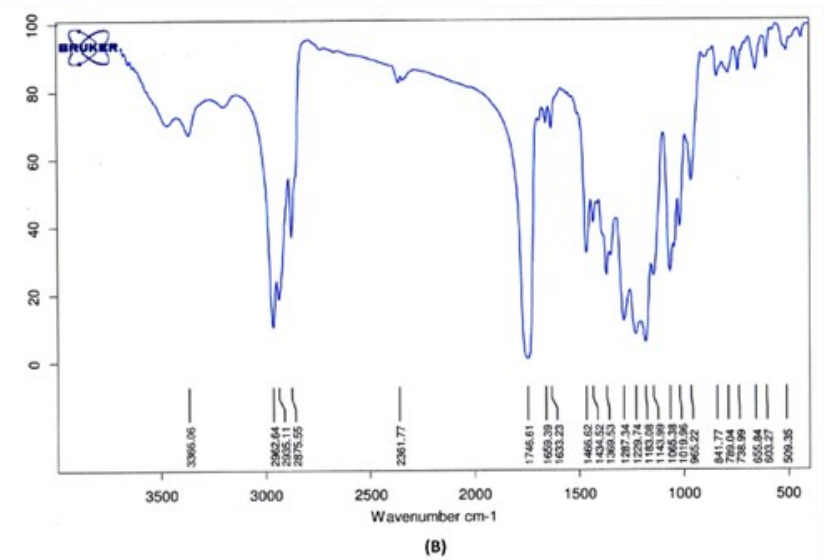

Figure 2. The Fourier Transform-infrared (FT-IR) Spectrums of the (A) Third Fraction, F3 and (B) Seventh Fraction, F7.

the antioxidant activity of polyphenols (ZielinskaBlizniewska et al., 2019).

\section{Conclusion}

Overall, the bioactive compound from water lettuce (Pistia stratiotes) was successfully extracted by methanol solvent. The methanol extract showed seven fractions after separation by thin-layer chromatography and column chromatography. Whereas, the third fraction possessed high antioxidant activity. The Fourier transform-infrared confirmed that the hydroxyl group of the polyphenols play an important role in their antioxidant activity.

\section{Conflict of interest}

The authors declare no conflict of interest.

\section{Acknowledgments}

We are thankful to the Indonesian Ministry of Research, Technology, and Higher Education (20172018) to support this study.

\section{References}

Alam, M.N., Bristi, N.J. and Rafiquzzaman, M. (2013). Review on in vivo and in vitro methods evaluation of antioxidant activity. Saudi Pharmaceutical Journal, 21(2), 143-152. https://doi.org/10.1016/ j.jsps.2012.05.002

Altemimi, A., Lakhssassi, N., Baharlouei, A., Watson, D. and Lightfoot, D. (2017). Phytochemicals: extraction, isolation, and identification of bioactive compounds from plant extracts. Plants, 6(4), 42. https://doi.org/10.3390/plants6040042

Anokwuru, C.P., Anyasor, G.N., Ajibaye, O., Fakoya, O. and Okebugwu, P. (2016). Effect of extraction solvents on phenolic, flavonoid, and antioxidant activities of three Nigerian medicinal plants. Nature and Science, 9(7), 53-61.
Benhammou, N., Bekkara, F.A. and Panovska, K.T. (2009). Antioxidant activity of methanolic extracts and some bioactive compounds of Atriplex halimus. Comptes Rendus Chimie, 12(12), 1259-1266. https:// doi.org/10.1016/j.crci.2009.02.004

Bouayed, J. and Bohn, T. (2010). Exogenous antioxidants-Double-edged swords in cellular redox state: health beneficial effects at physiologic doses versus deleterious effects at high doses. Oxidative Medicine and Cellular Longevity, 3(4), 228-237. https://doi.org/10.4161/oxim.3.4.12858

Do, Q.D., Angkawijaya, A.E., Tran-Nguyen, P.L., Huynh, L.H., Soetaredjo, F.E., Ismadji, S. and Ju, Y. -H. (2014). Effect of extraction solvent on total phenol content, total flavonoid content, and antioxidant activity of Limnophila aromatica. Journal of Food and Drug Analysis, 22(3), 296-302. https://doi.org/10.1016/j.jfda.2013.11.001

Foti, M.C. (2007). Antioxidant properties of phenols. Journal of Pharmacy and Pharmacology, 59(12), 1673-1685. https://doi.org/10.1211/jpp.59.12.0010

Kagan, I.A. and Flythe, M.D. (2014). Thin-layer chromatographic (TLC) separations and bioassays of plant extracts to identify antimicrobial compounds. Journal of Visualized Experiments, 85, e51411. https://doi.org/10.3791/51411

Khansari, N., Shakiba, Y. and Mahmoudi, M. (2009). Chronic inflammation and oxidative stress as a major cause of age-related diseases and cancer. Recent Patents on Inflammation and Allergy Drug Discovery, 3(1), 73-80. https:// doi.org/10.2174/187221309787158371

Lobo, V., Patil, A., Phatak, A. and Chandra, N. (2010). Free radicals, antioxidants and functional foods: Impact on human health. Pharmacognosy Reviews, 4 (8), 118. https://doi.org/10.4103/0973-7847.70902

Molyneux, P. (2004). The use of the stable free radical diphenylpicrylhydrazyl (DPPH) for estimating antioxidant activity. Songklanakarin Journal of Science and Technology, 26(2), 211-219. 
Ouhaddouch, H., Cheikh, A., Idrissi, M.O.B., Draoui, M. and Bouatia, M. (2019). FT-IR spectroscopy applied for identification of a mineral drug substance in drug products: Application to bentonite. Journal of Spectroscopy, 2019, 2960845. https:// doi.org/10.1155/2019/2960845

Phaniendra, A., Jestadi, D.B. and Periyasamy, L. (2014). Free radicals: properties, sources, targets, and their implication in various diseases. Indian Journal of Clinical Biochemistry, 30(1), 11-26. https:// doi.org/10.1007/s12291-014-0446-0

Sudirman, S., Herpandi, H., Lestari, S.D. and Wasahla, W. (2017). Phytochemicals screening and antioxidant activity of water lettuce (Pistia Stratiotes) extract. European Journal of Scientific Research, 146(3), 234-238.

Sudirman, S., Herpandi, H., Nopianti, R., Dwita Lestari, S., Wasahla, W. and Mareta, H. (2017). Phenolic contents, tannin, vitamin $\mathrm{C}$, and vitamin $\mathrm{E}$ of water lettuce (Pistia stratiotes). Oriental Journal of Chemistry, 33(6), 3173-3176. https:// doi.org/10.13005/ojc/330661

Triadisti, N., Sauriasari, R. and Elya, B. (2018). Antioxidant activity of fractions from Garcinia hombroniana Pierre leaves extracts. Pharmacognosy Journal, 10(4), 682-685. https://doi.org/10.5530/ pj.2018.4.112

Venkatesh, U., Javarasetty, C. and Murari, S.K. (2017). Purification and fractional analysis of methanolic extract of Wedelia trilobata possessing apoptotic and anti-leukemic activity. African Journal of Traditional, Complementary and Alternative Medicines, 14(3), 167-174. https://doi.org/10.21010/ ajtcam.v14i3.18

Zhao, Q.-C., Zhao, J.-Y., Ahn, D.U., Jin, Y.-G. and Huang, X. (2019). Separation and identification of highly efficient antioxidant peptides from eggshell membrane. Antioxidants, 8(10), 495. https:// doi.org/10.3390/antiox8100495

Zielinska-Blizniewska, H., Sitarek, P., MereczSadowska, A., Malinowska, K., Zajdel, K., Jablonska, M., Sliwinski, T. and Zajdel, R. (2019). Plant extracts and reactive oxygen species as two counteracting agents with anti- and pro-obesity properties. International Journal of Molecular Sciences 20(18), 4556. https://doi.org/10.3390/ ijms20184556 